\title{
Frontier efficiency of hospitals in United Arab Emirates: An application of data envelopment analysis
}

\author{
Ashraf Mahate ${ }^{1}$, Samer Hamidi *2 \\ ${ }^{1}$ Export Market Intelligence, Dubai Exports, Adjunct Professor in Economics, Hamdan Bin Mohammed Smart University, Dubai, \\ United Arab Emirates \\ ${ }^{2}$ Health Studies Department, School of Health and Environmental Studies, Hamdan Bin Mohammed Smart University, Dubai, \\ United Arab Emirates
}

Received: September 13, 2015

Accepted: October 7, 2015

Online Published: October 13, 2015

DOI: $10.5430 /$ jha.v5n1p7

URL: http://dx.doi.org/10.5430/jha.v5n1p7

\begin{abstract}
Background: Over the past four decades the United Arab Emirates (UAE) has undertaken a series of initiatives to improve the efficiency of hospitals. This study aims to examine the efficiency of private and public hospitals in the UAE. A clearer understanding of the technical efficiency of private and public hospitals will be important in shaping future policy reforms as well as assisting private investors that play an important role in the provision of healthcare within the UAE.

Methods: This study employs the Data Envelopment Analysis (DEA) technique to measure the efficiency of both private and public hospitals in the UAE. Efficiency scores are calculated using both Banker, Charnes, and Cooper (BCC) and Charnes, Cooper, and Rhodes (CCR) models. The inputs into the models are number of beds, numbers of doctors, dentists, nurses, pharmacists and allied health staff, and administrative staff, while the outputs are the number of treated inpatients, outpatients, and average length of stay.

Results: We find that public hospitals represent about a third of the total number of facilities but treat about $60 \%$ of the total number of patients. On the positive side we find that a third of the hospitals in the UAE to be efficient. The average technical efficiency of 96 hospitals is 59\% using BCC model and 48\% using CCR model. The results show no difference in the average efficiency scores between public and private hospitals, nor between foreign and domestically managed hospitals. We find that there is an almost equal probability to be an efficient or inefficient hospital in any of the emirates.

Conclusions: The study contributes to the existing body of literature by establishing baseline technical efficiency scores that could be used in monitoring the efficiency effects of future policy changes. About $41 \%$ to $52 \%$ of the production factors are wasted during the service delivery process in the hospitals. Using the existing amount of resources, the amount of delivered outputs can be doubled, which can significantly impact patient outcomes. This leads us to believe that the ownership itself and foreign management is not sufficient to bring about improvements in efficiency. Interventions to improve the quality of management in hospitals could help to improve efficiency. National and international benchmarking of hospital performance help to provide more insights on sources of hospital inefficiency.
\end{abstract}

Key Words: Technical efficiency, Data envelopment analysis, Hospital ownership, United Arab Emirates

\section{INTRODUCTION}

Governments throughout the world have been under increasing pressure to improve their provision of healthcare services while seeking to effectively employ their scare resources. At the same time the importance and political nature of healthcare has meant that individual governments' ability

${ }^{*}$ Correspondence: Samer Hamidi; Email: s.hamidi@ @bmsu.ac.ae; Address: Chair of Health Studies Department, School of Health and Environmental Studies, Hamdan Bin Mohammed Smart University, P.O. Box 71400, Dubai, United Arab Emirates. 
to compromise the quality and access of healthcare services is limited. In many countries the lack of finance especially in the aftermath of the international financial crisis has limited their ability to fund improvements but in the more prosperous Arab Gulf countries such as the United Arab Emirates (UAE) this has not tended to be the case. In the UAE the key problem in increasing hospital efficiency has been the ability to recruit and retain suitably qualified as well experienced healthcare professionals at all levels. Also, the young nature of Arab Gulf countries implies that these countries have a short history of healthcare development. One of the first hospitals in the UAE can be traced back to 1960 which was nothing more than a mud hut in the city of Al Ain staffed by two missionaries. At the time only half of the babies survived and one in three mothers died during childbirth. In addition to this malaria, tuberculosis, eye diseases and internal parasites were very common. ${ }^{[1]}$ Fifty-five years later the country has 96 private and public hospitals. Such a rapid increase in the provision of healthcare has meant that access and coverage are no longer an issue for the government. Instead the country is faced with a larger and more important problem of adapting the provision of its services to meet changing demographics and needs while trying to be efficient. The market demand for healthcare services in the UAE has meant that the private sector has been able to fill this gap alongside the government sector. On the one hand the market competitiveness of the private sector implies that it will deliver services in the most efficient manner. However, this has to be balanced with the fact that private sector operators will be motivated by profit and hence the provision of services may not always be allocated efficiently.

Although, the UAE health system is a blend of private and public provision it is tightly regulated by several regulators at the federal and emirate level. At the federal level there are two entities that regulate healthcare services namely the Ministry of Health (MOH) which was established in 1972 that is a year after the establishment of the country. The MOH is the ultimate regulatory authority over the entire UAE health sector as well as providing healthcare services. ${ }^{[2]}$ The $\mathrm{MOH}$ regulates the personnel that work in its hospitals as well as the private sector institutions. Then one has the National Health Council which oversees healthcare and standards across the UAE. The mandate of the Council is to co-ordinate health care initiatives of the public and private sectors on both the federal and local levels. The two emirates that have their own regulatory bodies namely Abu Dhabi and Dubai. In Abu Dhabi the emirate established the General Authority of Health Services in 2001. In 2007, the Authority was split into the Health Authority in Abu Dhabi (HAAD) and Abu Dhabi Health Services Company (SEHA). In Dubai, health care was regulated by the Dubai Department of Medical and Health Services which was established in 1972 and in 2007 replaced by the Dubai Health Authority (DHA).

Demographic factors such as aging population, high birth rate and expatriate majority have resulted in an increase in healthcare expenditures. The total health expenditures are expected to reach United Arab Emirates Dirhams (AED) 40 billion (US\$11 billion) in 2015 compared to AED 36 billion (US\$10 billion) in 2011. ${ }^{[3]}$ Free health coverage is universal for nationals, and laws have been instituted to ensure mandatory health insurance for non-nationals in the Emirates of Dubai and Abu Dhabi. With 31 public and 62 private hospitals and a number of new health care facilities planned, it is assumed that the country is well resourced. However, the delivery system is based on a primary health care approach and hence does not deal with the underlying issues leading to inefficiencies and inherent weaknesses. Second, despite the major improvements in the health care system during the last four decades, a very large number of patients elect to have their treatment overseas leading to under-utilized services and facilities. Over the last few years the government has sought to restrict the number of patients that elect to have overseas treatment. Efficiency levels may increase if overseas treatment is replacement with domestic provision thereby increasing the output with the same level of resources. Also, greater domestic provision of healthcare services will allow the country to develop more advanced areas of medical treatment. Other weaknesses within the UAE healthcare system that impact on efficiency levels are as follows:

(1) The absence of a single regulator for licensing medical staff thus limiting their ability to move from one employer to another. Also, a single regulator will ensure a level playing for all operators as opposed multiple standards and norms.

(2) There is a heavy usage of hospital based services even for minor illnesses and hence there needs to be a strengthening of primary health care and referral systems. This will allow the hospital based services to focus on acute illnesses.

(3) As the discussion above indicates that the bulk of illnesses in the UAE are due to lifestyle. Therefore, there needs to be a greater strengthening of health promotion and preventive programs.

(4) The UAE has excellent technical equipment, but a shortage of capable staff. The health care system depends on professionals from overseas, with expatriates comprising $80 \%$ of doctors and over $90 \%$ of nurses. There needs to be a program of developing local talent and a lower reliance on expatriate staff. 
In this respect a better understanding of the efficiency of the current level healthcare provision will allow healthcare managers as well as policy makers the ability to make better choices thus leading to the optimal usage of resources. Also, a better understanding of the relative differences in the delivery of healthcare services between the hospital ownership (private or public) and management type (foreign or domestic) will also help guide policy makers as to how best to include the involvement of the former if at all. The purpose of this study is to estimate the technical efficiency of both private and public hospitals in the UAE. In doing so the first objective of the study is to understand how the efficient hospitals in the UAE differ from the non-efficient ones. We developed the hypothesis that more efficient hospitals differ significantly from less efficient hospitals. So, we expect more efficient hospitals to better utilize their resources and hence have higher efficiency ratings. We expect more efficient hospitals to have lower staff and fixed assets and to have higher levels of output measured in form of patient visits and average length of stay. Second, this research seeks to understand whether there is a difference in the efficiency of private and public hospitals. Finally, we test whether foreign managed hospital provide efficiency benefits for the government.

\subsection{Literature review}

Prior studies have developed three main measures of efficiency namely technical, scale and productive. First, technical efficiency refers to the manner in which resources are employed so as to lead to the greatest level of output. As such technical efficiency emphasizes the technological aspects of an organization. In the case of healthcare services technical efficiency implies how the inputs which are essentially the physical assets, labour and financial resources are used to produce both intermediate and final outputs whereby examples of the former include number of patients, waiting time and so on while the latter include mortality rates, quality of life measures and so on. ${ }^{[4]}$ Secondly, one has allocative efficiency which refers how an organization is able to use inputs in an optimal manner based on their respective prices and technology. As such allocative efficiency measures how an organization is able to select the optimal combination of inputs to produce the greatest level of outputs. Third, one has productive or total economic efficiency which is the combined impact of technical and allocative efficiency.

The literature to date has tended to use a number of different methods to estimate the efficiency of healthcare service providers. In some cases the measure of efficiency are influenced by government policy. A typical example of this is the UK where the National Health Service has developed efficiency performance indicators and labour productivity measures to benchmark the different providers or trusts so

Published by Sciedu Press as to produce rankings. ${ }^{[5]}$ The problem with efficiency performance measures is that their selection can be subjective and also the final value is highly dependent on the weights used. A more objective and economics based approach is to estimate the production possibility frontier which is a locus of potentially efficient output combinations that an organization can employ at a particular point in time. The production possibility frontier is also considered the efficient frontier as any organization producing at that level is able to achieve an efficient combination of outputs with the given level of inputs.

There is no consensus as to the best method of measuring efficiency. Past studies have identified two methods, namely, non-parametric methods initiated by Charnes et al. ${ }^{[6]}$ and a parametric technique developed by Aigner. ${ }^{[7]}$ Parametric measures focus on economic optimization, while nonparametric techniques examine technological optimization. The major advantage of using non-parametric techniques, and more specifically the Data Envelopment Analysis (DEA), is that it avoids having to measure output prices which are not always available.

The modelling approach employed impacts on the selection of data which in turn can affect the results of a study. ${ }^{[8]}$ From a public policy viewpoint the results of efficiency studies can then impact the manner in which hospitals operate. For instance using length of stay as an output measure could lead to hospitals selecting less patients with complicated illnesses. In order to avoid such a situation the modelling needs to be comprehensive in its nature so as not to prejudice the over use of any single input or output. Another issue that arises in healthcare is that the actual data on outcomes does not always exist in the public arena. In other words the actual outcome of a particular treatment is not publicly available. Due to the lack of publicly available data prior studies have assumed that the health outcomes are the same as the hospital providing the treatment. ${ }^{[9]}$ This assumption makes little difference where the hospital provides treatment that by and large tends to be successful and error free. However, where hospitals are of a poor quality such an assumption may not hold and could positively reward poor performing hospitals. ${ }^{[10]}$ However, due to the confidential nature of medical information it is not possible to have data regarding re-admissions. In the absence of such data prior studies have used raw counts in capturing the health services as output. A similar issue arises with inputs whereby raw counts for human resources are used without differentiating between skill, experience or qualification level.

\subsubsection{Hospital ownership}

Hospital ownership can essentially be divided into two broad groups namely those that are operated for profit and non- 
profit whereby the former can be owned by the public sector, while the latter are owned by private sector investors. The key difference between the two groups is that private for profit hospitals use performance measures and targets which differ fundamentally from non-profit ones and this impact the principal agent relationship. Both private and public hospital face the same principal agent problem whereby managers or agents seek to maximize their own utility rather than that of the organization or its owners or principals. ${ }^{[11]}$ However, it is argued that private for-profit hospitals are better able to deal and solve the principal-agent problem by linking the manager's and perhaps the clinical staff remuneration to performance of the hospital which is measured as the overall profits. In a non for profit institution such type of remuneration structures are not possible and hence individuals do not have an incentive to exhibit efficient behaviour. The linking of remuneration to performance tends to ensure that private hospitals achieve a higher level of efficiency than public nonprofit ones. ${ }^{[12]}$ Traditional finance theory argues that external mechanisms are also important in private for profit organizations to ensure that the agent's motivations are aligned with those of principals. In a private hospital there is always the possibility that the owners may sell their shares if they are not satisfied with managerial performance. Similarly, poor performing organizations may be takenover by better ones leading to a displacement of managerial staff. Even worse is the threat that of bankruptcy which again will not only displace managerial staff but tarnish their reputation. On the other side of the spectrum managerial staff that perform well are more likely to be recruited by larger organizations. ${ }^{[13]} \mathrm{In}$ the case of public hospitals there is rarely the fear of takeover, bankruptcy or sale of assets to a private sector entity. It's not just the difference in agency theory but also the adherence to economic principles that differ between for profit and nonprofit hospitals. Weisbrod ${ }^{[14]}$ argues that the non-for-profit hospitals do not have the incentive to maximize profit hence do not produce at the marginal cost equals marginal revenue point. This implies that a for profit hospital will cease to supply services beyond the profit maximizing point while this is not true for a non-profit institution which has welfare benefit objectives. ${ }^{[15]}$ Furthermore, Sloan ${ }^{[16]}$ argues that in non-profit organizations the performance measures tend to be vague and at times contradictory leading to a lower efficiency level.

Hollingsworth ${ }^{[17]}$ in an extensive review of 317 published papers using the DEA technique for the period 1980 to 2006 found that 39 studies concluded that non-for profit hospitals to be more efficient than for profit ones. The larger number i.e. $82 \%$ of studies tended to support the argument that for profit hospitals were more efficient than non-profit ones. In a smaller review of 16 studies Shen et al. ${ }^{[18]}$ find no support for the argument that for profit hospitals operate more efficiently than non-for profit ones. The sample of studies examining hospitals in developed countries generally indicate that for profit institutions are more likely to be efficient compared to non for profit ones. However, in developing countries the same may not be true and Basu et al. ${ }^{[19]}$ review 102 prior studies conducted in low and middle income countries. Interestingly, Basu ${ }^{[19]}$ find that efficiency levels in private hospitals tended to be lower than in the public sector. The main cause of the inefficiency of for profit hospitals was their irrational behaviour of carrying out unnecessary testing and treatment. Our literature review shows a gap in knowledge regarding young resource rich countries such as the UAE and the efficiency between private and public hospitals.

\subsubsection{Hospital management}

One of the key themes in healthcare recent years has been the drive to improve the management of hospitals. It is generally argued that the management of a healthcare facility is a complex affair involving highly educated and specialized clinical staff reporting to non-clinical management staff. Such an environment requires management to have skills that go beyond simple resource management. At the same time increased patient demands implies that services need to be continuously enhanced and are regularly benchmarked against peers. Dorgan et al. ${ }^{[20]}$ surveyed an extensive sample of 1,200 hospitals in Canada, France, Germany, Italy, Sweden, the United Kingdom, and the United States and find a very strong relationship between management practice scores and clinical outcomes. The study finds that hospitals with higher management practice scores achieved lower mortality rates, higher patient satisfaction and better financial performance. The authors highlight that for the UK this can be represented as a one-point improvement in the management-practice score to lead a $10 \%$ reduction mortality rates.

An important role of management is not simply to lead but to develop a culture that fosters and allows for performance to be enhanced. Davies et al. ${ }^{[21]}$ examined the relationship between senior management team culture and organizational performance for a sample of 97 UK hospitals. Their results support the argument that there is a strong relationship between organizational culture and performance. Part of organizational culture is to use set the appropriate governance structure. Buchner et al. ${ }^{[22]}$ examine the roles governing boards on hospital performance especially in the area of quality and financial performance. Their results show that different governing board types significant impact the level of hospital performance. The fact that the governing board sets strategy or at least reviews it has a positive effect on hospital performance. Also, the authors argue that the greater 
the diversity of the governing board the more effective its impact on the performance of the hospital. In the case of the UAE there has always been a strong emphasis on expatriates playing an important role in the management of hospitals. This is not surprising bearing in mind that expatriates account for $88 \%$ of the population. However, in recent years there has been a realization among decision makers that new and internationally proven management techniques and procedures need to be implemented. As a result a number of public hospitals are now being managed by well-known foreign operators such as the John Hopkins Institute.

\section{Methodology}

DEA is a nonparametric method used in this study to estimate the efficiency of 96 private and public hospitals in the UAE. The most prevalent DEA model formulation is the model developed by Charnes, Cooper, and Rhodes (CCR model), ${ }^{[6]}$ and modified by Banker, Charnes, and Cooper (BCC model). ${ }^{[23]}$ In order to examine whether the hospitals in this study increased the output of resources while keeping the level of inputs constant, we used an output oriented. For computing efficiency, we use two DEA models: CCR and BCC models. The CCR model works on the concept of constant-return-to-scale, while the BBC model works on the concept of variable-return-to-scale. The efficiency computed from BCC model is pure technical efficiency (PTE) ${ }^{[24]}$ whereas the efficiency computed from the CCR model is the overall technical efficiency (OTE). Scale efficiency (SE) means the efficiency due to scale difference between constantreturn-to-scale and variable-return-to-scale, ${ }^{[25]}$ it measures the impact of scale size on efficiency of a hospital by dividing the CCR efficiency over BCC efficiency. ${ }^{[23]}$ OTE reflects the ability of a hospital to obtain the maximum output from a given set of inputs. PTE reflects the proportion of technical efficiency which is attributed to efficient conversion of inputs to output given the scale size. Linear programming is used to calculate the relative efficiency for each hospital. Efficiency scores vary between 0 and $100 \%$. Hospitals with a score of $100 \%$ are technically efficient. The basis of the DEA technique is a measure of efficiency derived from a ratio of weighted outputs to weighted inputs as shown in Equation 1 below, where:

$$
h=\frac{\sum_{r=1}^{t} u_{r} y_{r j_{0}}}{\sum_{i=1}^{m} v_{i} x_{i j_{0}}}
$$

$j=1,2, \ldots \ldots, n$, decision making units; $r=1,2, \ldots \ldots, t$, outputs; $i=1,2, \ldots \ldots, \mathrm{m}$, inputs; $y_{r j}=$ amount of output $r$ for unit $j ; x_{r j}=$ amount of input $r$ for unit $j$; $u_{r}=$ weight assigned to output $r ; v_{r}=$ weight assigned to input $r$

The weights $u$ and $v$ according to Charnes et al. ${ }^{[6]}$ is the CCR Published by Sciedu Press model are assigned so as to produce a measure of efficiency for each decision making unit (hospital). The weights are calculated by maximizing the efficiency ratio of the hospital subject to the constraint that the efficiency ratios of all the hospitals computed with the same weights have an upper bound of 1 . There is no general consensus as to which inputs and outputs to use when estimating hospital efficiency and the choice is related to the hospital model used. As discussed in the literature review section, we believe that a production model of a hospital best describes the case in the UAE and hence they are assumed to convert inputs into outputs using their preferred production process. As in traditional economics the inputs are divided into three broad types namely labour (e.g. doctors, nursing, administrative etc.), capital (buildings, equipment $e t c$.) and instead of land we substitute resources (e.g. drugs, consumables etc.). Ideally one would like to use the final outcome which for any society is the improvement in the health of its population. However, two issues arise in measuring such an output. First, it is seldom possible to trace the improvement in the population to a particular hospital. This is especially the case where the population may be able to use a number of different hospitals in their treatment. Second, for countries such as the UAE such a final output measure may not be suitable because $90 \%$ of the population are expatriate and transient in nature. Therefore, in most cases it is not possible to determine the impact on the final output for such a population base. In the absence of the ability to measure the final outcome we use the intermediate measure which tends to be aspects such as the consultations, surgeries etc. The variables selected for this study are some of the most commonly used for input and output variables affecting hospital efficiency as found in the published research. In modelling hospital production we used six input and three output variables in our study. The inputs into the model are number of beds, numbers of doctors, dentists, nurses, pharmacists and allied health staff, and administrative staff, while the outputs are the number of treated inpatients, outpatients, and average length of stay were used as output variables. Data were collected from the annual reports of MOH, DHA, and HAAD in 2012. ${ }^{[26,27]}$ The input and out variables for each hospital are listed in Table 1.

\section{Results}

We find that across the different emirates there is very little difference as far as the size of hospital is concerned. However, we find that public hospitals are far larger than those owned by the private sector. In terms of doctors the difference is two and half times as large, in the case of nurses, hospital beds its almost four times and for in and out patients 
its one and half times as large. These findings lead us to believe that private sector operators tend to have smaller and more specialized services. As such private sector operators do not offer a comprehensive range of specialties and tend to focus on areas which require short in-patient treatment. We find that private sector hospitals have an average in hospital stays of 1.48 days compared to 14 days for public hospitals (see Table 2).

Table 1. Input and output variables and operating definitions

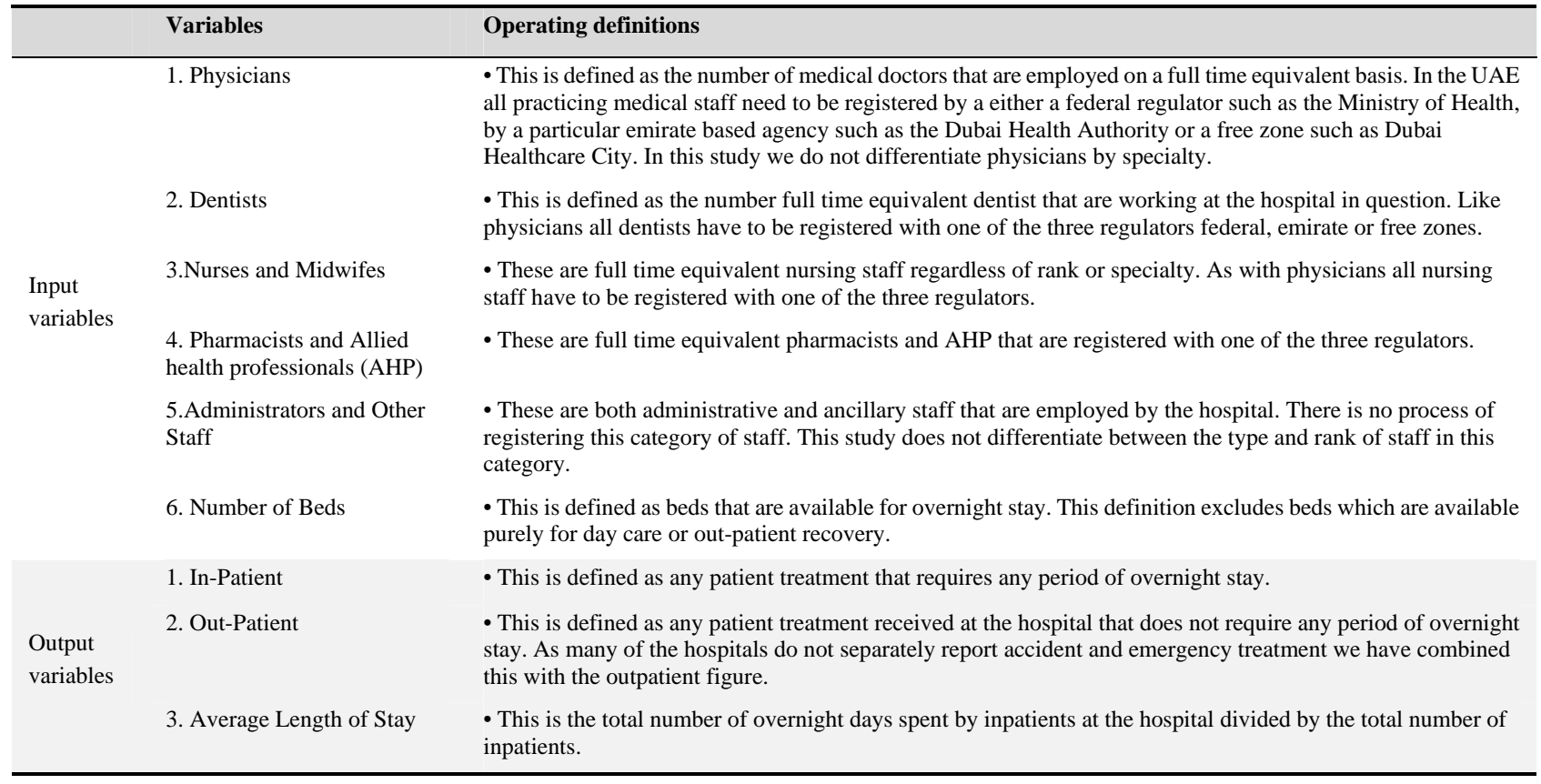

Note. A hospital is defined as one which has the appropriate license from the regulatory authority

We find that public hospitals represent about a third of the total number of facilities but treat about $60 \%$ of the total number of patients. Also, we find that public hospitals tend to be better staffed than private ones. In the case of nurses to doctors the ratio is 3 to 1 for the government sector while it is only 2 to 1 for private sector establishments. The most striking difference in staffing between the two is in the case of pharmacists whereby the average value for public hospitals is one for every two doctors while in the private the ratio is one pharmacist for every ten doctors.

Our results show that there is a very wide distribution of efficiency scores for the 96 hospitals in our sample as shown in Figure 1.

Table 3 depicts the efficiency score of hospitals using CCR and BCC models applying DEA methodology. The results show no difference in the average efficiency scores between public and private hospitals. The tests of differences in means, shown in Table 4, do not find any statistically significant difference in the efficiency scores between public and private hospitals.

Our hypothesis seeks to understand whether efficient hospitals differ significantly from less efficient hospitals. In order to understand the differences between the two groups of hos- pitals we partition the sample into three groups namely the 30 best and 30 least efficient hospitals. We then compared these two groups to identify differentiating attributes between the two groups. The results from this comparison are provided in Table 5.

Our results in Table 6 find no statistically significant difference between the performance of domestic and foreign managed hospitals.

\section{DisCUSSION}

As discussed in the methodology section of this paper that, we calculate two alternative measures of efficiency, namely the CCR and BBC. The difference in assumptions between the two measures will lead to small differences in the results. The correlation between the CCR and BBC scores for our study is about 0.78 implying that more than three quarters of the sample have similar rankings and move in the same direction. On the positive side we find that a third of the hospitals in the UAE to be efficient. On the other extreme we find that half the hospitals are less than half as efficient as the top hospital. This result implies that by and large the healthcare sector in the UAE is not efficient. More importantly, the UAE healthcare system displays signs of a dual system whereby some hospitals are efficient while others are not and 
the gap between them is substantial. With the exception of UAQ there is no real statistically significant difference in the efficiency scores between the different emirates. In the case of UAQ the fact that it has a single hospital has tended to skew the result somewhat. More interesting is that fact that there appears to be a large and statistically significant difference in the efficiency scores of the three government operators. Our results show that DHA hospitals are by far the most efficient with an average score of 96 using both the
CCR and BCC measures. We find that SEHA hospitals to be the least efficient with an average score of 24 and 48 using both the CCR and BCC measures, respectively. Our tests of difference in means finds there to be statistically significant difference in efficiency scores between DHA and SEHA at the $1 \%$ level. We also find that there is a statically significant difference between SEHA and MOH hospitals at the 5\% level.

Table 2. Summary statistics

\begin{tabular}{|c|c|c|c|c|c|c|c|c|c|c|c|}
\hline & \multirow{2}{*}{$\begin{array}{l}\text { Number of } \\
\text { Hospitals }\end{array}$} & \multirow[b]{2}{*}{ Measure } & \multicolumn{6}{|c|}{ Inputs } & \multicolumn{3}{|c|}{ Outputs } \\
\hline & & & Doctors & Dentists & Nurses & Pharmacists & $\begin{array}{l}\text { Technicians } \\
\text { Admin, Clerks) }\end{array}$ & $\begin{array}{l}\begin{array}{l}\text { Number } \\
\text { of Beds }\end{array} \\
\end{array}$ & Inpatients & $\begin{array}{l}\text { Total } \\
\text { Outpatients }\end{array}$ & $\begin{array}{l}\text { Average Length } \\
\text { of Stay in days }\end{array}$ \\
\hline \multirow{3}{*}{ Gov't } & \multirow{3}{*}{31} & Mean & 125 & 2.97 & 381 & 61 & 208 & 195 & 7,188 & 170,617 & 14.12 \\
\hline & & Median & 77 & 2.00 & 195 & 18 & 111 & 148 & 5,938 & 139,300 & 4.11 \\
\hline & & St Dev. & 143 & 4.63 & 415 & 107 & 276 & 162 & 7,701 & 137,980 & 46.13 \\
\hline \multirow{3}{*}{ Private } & \multirow{3}{*}{65} & Mean & 51 & 3.37 & 99 & 6 & 106 & 55 & 4,658 & 124,524 & 1.48 \\
\hline & & Median & 35 & 2.00 & 72 & 4 & 67 & 38 & 2,601 & 75,833 & 1.11 \\
\hline & & St Dev. & 43 & 3.88 & 92 & 7 & 131 & 58 & 5,337 & 150,486 & 1.94 \\
\hline \multirow{3}{*}{$\begin{array}{l}\text { Abu } \\
\text { Dhabi }\end{array}$} & \multirow{3}{*}{56} & Mean & 97 & 3.76 & 258 & 61 & 145 & 130 & 5,181 & 170,816 & 8.14 \\
\hline & & Median & 50 & 3.00 & 138 & 18 & 67 & 80 & 3,450 & 126,772 & 2.33 \\
\hline & & St Dev. & 116 & 4.74 & 341 & 107 & 226 & 142 & 6,422 & 161,374 & 34.73 \\
\hline \multirow{3}{*}{ Dubai } & \multirow{3}{*}{28} & Mean & 70 & 3.31 & 175 & 13 & 127 & 95 & 5,735 & 148,076 & 6.86 \\
\hline & & Median & 48 & 2.00 & 114 & 8 & 88 & 72 & 3,450 & 119,149 & 1.91 \\
\hline & & St Dev. & 66 & 3.94 & 222 & 14 & 129 & 100 & 6,464 & 141,793 & 32.08 \\
\hline \multirow[t]{2}{*}{ Sharjah } & \multirow[t]{2}{*}{17} & Median & 40 & 2.00 & 86 & 6 & 71 & 50 & 3,393 & 95,279 & 1.49 \\
\hline & & St Dev. & 44 & 3.78 & 106 & 7 & 122 & 65 & 5,279 & 142,329 & 30.19 \\
\hline \multirow{3}{*}{ RAK } & \multirow{3}{*}{6} & Mean & 40 & 1.75 & 142 & 10 & 80 & 130 & 6,102 & 98,884 & 67.38 \\
\hline & & Median & 27 & 1.50 & 110 & 11 & 69 & 120 & 5,030 & 99,976 & 5.12 \\
\hline & & St Dev. & 44 & 2.06 & 132 & 8 & 74 & 83 & 5,970 & 82,030 & 126.70 \\
\hline \multirow{3}{*}{ Fujairah } & \multirow{3}{*}{5} & Mean & 52 & 3.31 & 103 & 6 & 106 & 59 & 4,766 & 126,411 & 1.53 \\
\hline & & Median & 35 & 2.00 & 76 & 5 & 67 & 40 & 2,900 & 76,653 & 1.18 \\
\hline & & St Dev. & 44 & 3.84 & 98 & 7 & 129 & 61 & 5,293 & 148,596 & 1.94 \\
\hline \multirow{3}{*}{ UAQ } & \multirow{3}{*}{1} & Mean & 77 & 0 & 198 & 12 & 111 & 156 & 5,318 & 134,085 & 4.5 \\
\hline & & Median & 77 & 0 & 198 & 12 & 111 & 156 & 5,318 & 134,085 & 4.5 \\
\hline & & St Dev. & $\mathrm{n} / \mathrm{a}$ & $\mathrm{n} / \mathrm{a}$ & $\mathrm{n} / \mathrm{a}$ & $\mathrm{n} / \mathrm{a}$ & $\mathrm{n} / \mathrm{a}$ & $\mathrm{n} / \mathrm{a}$ & $\mathrm{n} / \mathrm{a}$ & $\mathrm{n} / \mathrm{a}$ & $\mathrm{n} / \mathrm{a}$ \\
\hline \multirow{3}{*}{ Ajman } & \multirow{3}{*}{2} & Mean & 54 & 3.25 & 114 & 8 & 108 & 65 & 5,137 & 130,769 & 54.28 \\
\hline & & Median & 37 & 2.00 & 81 & 5 & 69 & 50 & 3,043 & 93,161 & 37.00 \\
\hline & & St Dev. & 44 & 3.85 & 104 & 8 & 129 & 60 & 5,376 & 147,386 & 44.37 \\
\hline \multirow[t]{2}{*}{$\mathrm{MOH}$} & \multirow[t]{2}{*}{15} & Median & 44 & 1.00 & 193 & 12 & 108 & 138 & 6,100 & 134,085 & 4.09 \\
\hline & & St Dev. & 43 & 2.90 & 114 & 8 & 52 & 68 & 4,627 & 68,215 & 65.91 \\
\hline & & Mean & 172 & 4.67 & 462 & 129 & 324 & 206 & 3,667 & 202,400 & 4.78 \\
\hline SEHA & 12 & Median & 100 & 2.00 & 274 & 65 & 146 & 135 & 1,500 & 128,250 & 4.60 \\
\hline & & St Dev. & 190 & 6.40 & 505 & 150 & 411 & 208 & 4,279 & 196,117 & 2.65 \\
\hline & & Mean & 222 & - & 813 & 39 & 244 & 356 & 18,813 & 224,908 & 4.75 \\
\hline DHA & 4 & Median & 215 & - & 847 & 45 & 259 & 379 & 21,246 & 247,701 & 3.50 \\
\hline & & St Dev. & 146 & - & 536 & 29 & 144 & 185 & 13,996 & 108,218 & 3.59 \\
\hline
\end{tabular}

Note. UAQ has only one hospital and hence the standard deviation cannot be calculated

We find that there is an almost equal probability to be an efficient or inefficient hospital in any of the emirates. Therefore, we do not find any emirate specific factors such as local healthcare regulation, oversight from inspectors, or patient behavior to impact on the efficiency scores. We speculate that the differing regulation or oversight in each emirate imposes an administrative cost but does not impact the efficiency of the hospital. Similarly, we find an equal proportion of private hospitals in both the best and least performing groups. This leads us to believe that the ownership itself is not sufficient to 
bring about improvements in efficiency. One reason for this is that private sector hospitals may suffer from the agency conflict discussed in the literature review section above. This study finds that SEHA and MOH hospitals are likely to be both efficient and inefficient in almost the same proportion. However, one of our most interesting results is that DHA hospitals are not only highly efficient but none of them are inefficient. We believe that DHA hospitals have attributes that make them far more efficient than their peers. Decomposing the public hospitals one finds that the $\mathrm{MOH}$ operates the smaller sized facilities when compared to SEHA or DHA. However, we believe that this is reflective of the population densities rather than any predetermined plan. $\mathrm{MOH}$ is responsible for healthcare outside the emirate of Abu Dhabi. Some of the emirates such as UAQ are very small indeed and may not be able to sustain a larger facility. We find that DHA has by far the largest facilities on average and treats the highest number of patients. Interestingly, DHA treats the highest number of inpatients but its average hospital stays is 4.75 days compared to 24.1 days for MOH. This leads us to speculate that DHA hospitals may due to the sheer force of patient numbers could be adopting practices that lead to a greater throughput and thus increased efficiency than hospitals where such pressures do not exist.

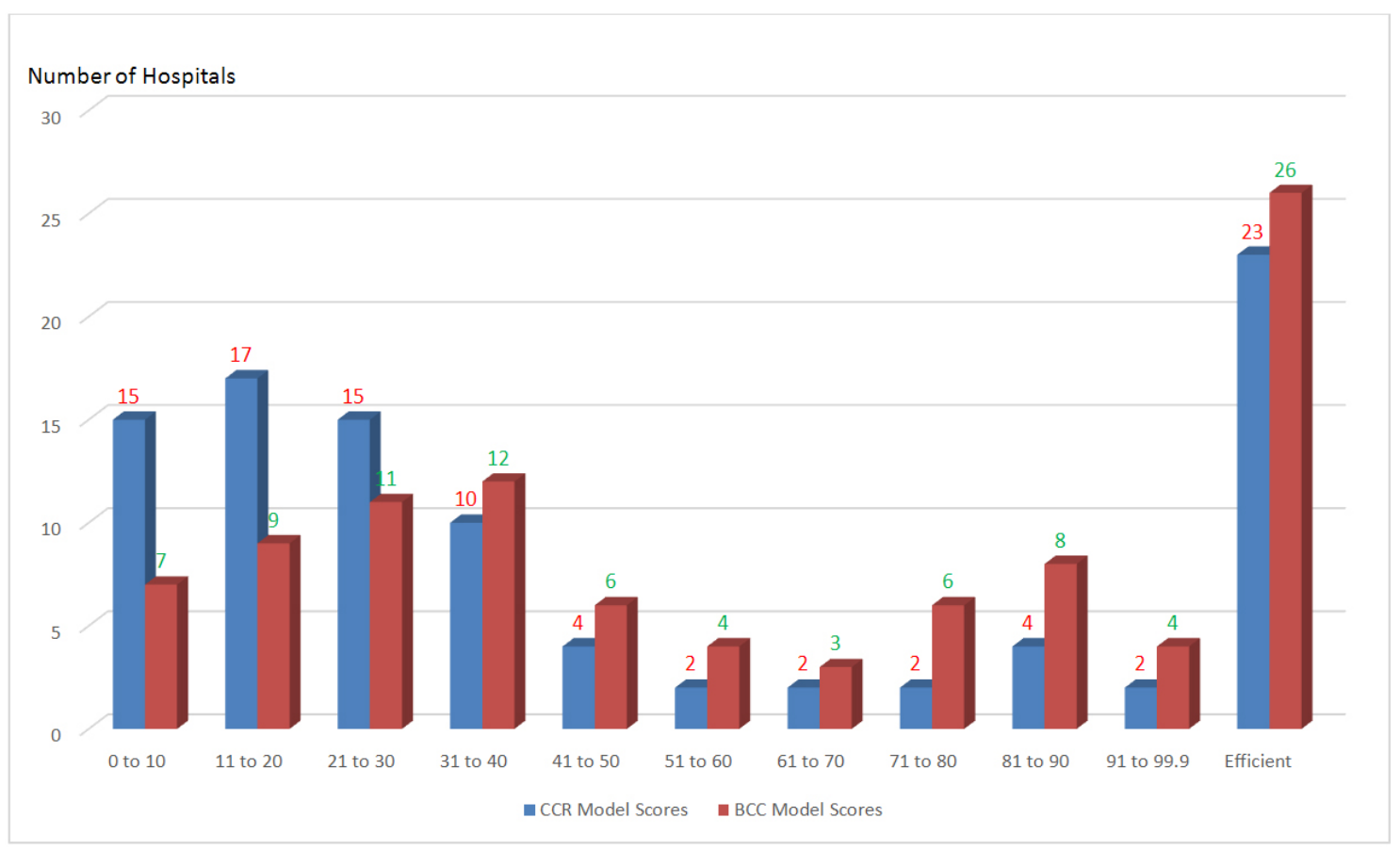

Figure 1. Distribution of efficiency scores

Table 3. Efficiency scores

\begin{tabular}{|c|c|c|c|c|c|c|c|}
\hline & \multirow{2}{*}{$\begin{array}{l}\text { Number of } \\
\text { Hospitals }\end{array}$} & \multicolumn{3}{|c|}{$\overline{C C R}$} & \multicolumn{3}{|c|}{ BCC } \\
\hline & & Mean & Median & St Dev. & Mean & Median & St Dev. \\
\hline Gov't & 31 & 47.29 & 31.33 & 37.00 & 59.48 & 56.72 & 34.80 \\
\hline Private & 65 & 47.98 & 31.21 & 35.17 & 58.74 & 53.84 & 34.78 \\
\hline Abu Dhabi & 56 & 49.44 & 37.55 & 37.18 & 61.87 & 71.86 & 34.92 \\
\hline Dubai & 28 & 47.27 & 30.73 & 35.37 & 54.49 & 44.41 & 32.39 \\
\hline Sharjah & 17 & 38.96 & 25.57 & 34.50 & 57.41 & 71.19 & 40.57 \\
\hline RAK & 6 & 39.96 & 26.22 & 32.30 & 64.21 & 55.06 & 29.12 \\
\hline Fujairah & 5 & 41.22 & 26.22 & 33.74 & 53.32 & 43.36 & 44.95 \\
\hline UAQ & 1 & 89.22 & 89.22 & $\mathrm{n} / \mathrm{a}$ & 89.02 & 89.02 & $\mathrm{n} / \mathrm{a}$ \\
\hline Ajman & 2 & 52.19 & 33.65 & 35.95 & 89.14 & 89.14 & 15.37 \\
\hline $\mathrm{MOH}$ & 15 & 53.93 & 34.41 & 36.50 & 59.48 & 56.72 & 34.80 \\
\hline SEHA & 12 & 24.43 & 20.03 & 12.96 & 47.82 & 34.98 & 29.64 \\
\hline DHA & 4 & 96.28 & 98.73 & 5.87 & 96.28 & 98.73 & 5.87 \\
\hline
\end{tabular}


Table 4. Tests of differences in means

\begin{tabular}{|c|c|c|c|c|c|c|c|c|c|c|c|c|c|c|}
\hline & CCR & & & & & & & BCC & & & & & & \\
\hline \multicolumn{15}{|c|}{ Panel A: Between Private and Public Hospitals } \\
\hline & Private & & & & & & & Private & & & & & & \\
\hline Government & -0.086 & & & & & & & 0.097 & & & & & & \\
\hline \multicolumn{15}{|c|}{ Panel B: Between Emirates } \\
\hline & $\mathrm{AD}$ & Dxb & Shj & RAK & Fuj & UAQ & Ajman & $\mathrm{AD}$ & Dxb & Shj & RAK & Fuj & UAQ & Ajman \\
\hline \multicolumn{15}{|l|}{ Abu Dhabi } \\
\hline Dubai & 0.260 & & & & & & & 0.959 & & & & & & \\
\hline Sharjah & 1.077 & 0.776 & & & & & & 0.410 & -0.25 & & & & & \\
\hline RAK & 0.673 & 0.495 & -0.07 & & & & & -0.18 & -0.77 & -0.44 & & & & \\
\hline Fujairah & 0.517 & 0.367 & -0.13 & -0.06 & & & & 0.442 & 0.056 & 0.183 & 0.466 & & & \\
\hline UAQ & -8.01 & 6.273 & -6.00 & -3.20 & -3.64 & & & -5.86 & -5.67 & -3.21 & -2.09 & -1.78 & & \\
\hline Ajman & -0.11 & -0.19 & -0.49 & -0.43 & -0.38 & 1.456 & & 1.402 & -2.79 & -2.16 & -1.54 & -1.57 & -0.01 & \\
\hline \multicolumn{15}{|c|}{ Panel C: Between Health Authorities } \\
\hline & MOH & & & & & SEHA & & $\mathrm{MOH}$ & & & & & SEHA & \\
\hline \multicolumn{15}{|l|}{$\mathrm{MOH}$} \\
\hline DHA & -4.290 & & & & & & & -3.893 & & & & & & \\
\hline SEHA & 2.909 & & & & & & & 0.672 & & & & & & \\
\hline
\end{tabular}

Table 5. Difference between top 30 efficient and non-efficient hospitals

\begin{tabular}{|c|c|c|c|c|}
\hline & \multicolumn{2}{|c|}{ Bottom 30 Hospitals by Efficiency Scores } & \multicolumn{2}{|c|}{ Top 30 Hospitals by Efficiency Scores } \\
\hline & CCR & BCC & CCR & BCC \\
\hline Emirate & $\begin{array}{l}\text { Abu Dhabi = } 12 \\
\text { Dubai = } 9 \\
\text { Sharjah = } 6 \\
\text { Fujairah = } 2 \\
\text { RAK = } 1\end{array}$ & $\begin{array}{l}\text { Abu Dhabi = } 12 \\
\text { Dubai = } 9 \\
\text { Sharjah = } 6 \\
\text { Fujairah = } 2 \\
\text { RAK = } 1\end{array}$ & $\begin{array}{l}\text { Abu Dhabi = } 11 \\
\text { Dubai = } 7 \\
\text { Sharjah = } 4 \\
\text { Ajman = } 1 \\
\text { UAQ = } 1 \\
\text { Fujairah = } 2 \\
\text { RAK = } 2\end{array}$ & $\begin{array}{l}\text { Abu Dhabi = } 12 \\
\text { Dubai = } 7 \\
\text { Sharjah = } 6 \\
\text { Ajman = } 1 \\
\text { Fujairah = } 2 \\
\text { RAK = } 2\end{array}$ \\
\hline Ownership & $\begin{array}{l}\text { Private = } 21 \\
\mathrm{MOH}=3 \\
\mathrm{SEHA}=6\end{array}$ & $\begin{array}{l}\text { Private = } 22 \\
\mathrm{MOH}=2 \\
\text { SEHA }=6\end{array}$ & $\begin{array}{l}\text { Private }=21 \\
\text { SEHA }=6 \\
\text { DHA }=4\end{array}$ & $\begin{array}{l}\text { Private = } 22 \\
\mathrm{MOH}=4 \\
\mathrm{SEHA}=6 \\
\mathrm{DHA}=3\end{array}$ \\
\hline Management & $\begin{array}{l}\text { Domestic }=28 \\
\text { Foreign }=2\end{array}$ & $\begin{array}{l}\text { Domestic }=28 \\
\text { Foreign }=2\end{array}$ & $\begin{array}{l}\text { Domestic = } 29 \\
\text { Foreign }=1\end{array}$ & $\begin{array}{l}\text { Domestic }=28 \\
\text { Foreign }=2\end{array}$ \\
\hline
\end{tabular}

Table 6. Efficiency scores by foreign and domestic management

\begin{tabular}{lllllllll}
\hline & \multicolumn{3}{c}{ CCR } & & \multicolumn{3}{c}{ BCC } \\
\cline { 2 - 4 } \cline { 6 - 8 } & Mean & Median & St Dev. & & Mean & Median & St Dev. \\
\hline Foreign Managed & 48.45 & 33.65 & 37.50 & & 58.75 & 52.45 & 35.22 \\
Domestically Managed & 34.5 & 22.5 & 30.1 & & 67.7 & 77.04 & 30.47 \\
Test of Difference in Means & 1.227 & & & & -0.786 & & \\
\hline
\end{tabular}

Our second hypothesis was to compare the performance of privately owned healthcare providers with non-privately owned healthcare providers. As we have discussed above we find no evidence to support this hypothesis and our results show that inefficient hospitals are equally likely to be managed by privately owned operators. In our discussion above we have explained that we believe that private sector operators have not been able to adequately deal with the agency conflict or implement appropriate governance structures. Our final hypothesis seeks to examine whether foreign managed hospitals are more efficient than domestically managed hospitals. Our results in Table 6 find no statistically significant 
difference between the performance of domestic and foreign managed hospitals. Furthermore Table 5 shows that there are two foreign owned hospitals in the least efficient group as well as two in the most efficient group. Therefore, one can argue that foreign managed hospitals do not bring any additional efficiency gains. This study did not carry out a time series analysis to understand whether foreign managed hospitals have improved their performance over time and this may be an area that future research may pursue.

\section{CONCluSions AND RECOMMENDATIONS}

Technical efficiency analysis is used as a review tool to assess decisions regarding allocation of human and capital resources in hospitals. This study measured technical efficiency of hospitals in UAE using DEA methodology. Our study contributes to the existing body of literature by establishing baseline PTE and OTE scores that could be used in monitoring the efficiency effects of future policy changes. On the positive side we find that a third of the hospitals in the UAE to be efficient. On the other extreme we find that half the hospitals are less than half as efficient as the top hospital. The average technical efficiency of 96 hospitals was about 59\% using BCC model and 48\% using CCR model. Despite continued government investment in the hospital sector through capital hospital expansion, hiring more workforce, and promotion of new technology, hospitals has remained relatively inefficient. About $41 \%$ (BCC model) to $52 \%$ (CCR model) of the production factors are wasted during the service delivery process in UAE hospitals. Using the existing amount of resources, the amount of delivered outputs can be doubled, which can significantly impact patient outcomes.
This result implies that by and large the healthcare sector in the UAE is not efficient. More importantly, the UAE healthcare system displays signs of a dual system whereby some hospitals are efficient while others are not and the gap between them is substantial. We find that inefficient hospitals are equally likely to be managed by privately owned operators. In its pursuit to improve the efficiency and effectiveness of its healthcare facilities some healthcare authorities have outsourced the management of hospitals to overseas contractors. We assume that foreign managed hospitals will be more efficient than domestic ones due to their greater experience and knowledge of managing such types of operations, however, our results also shows that there is no statistically significant difference between the performance of domestic and foreign managed hospitals. To address inefficiency in hospital, policy makers may increase output in terms of treated patients, reduce inputs, and change organization and processes in hospitals. The efficiency scores provide insight into mismanagement of available resources. Interventions to improve the quality of management in hospitals could help to improve efficiency. National and international benchmarking of hospital performance help to provide more insights on sources of hospital inefficiency.

This article was an attempt to measure technical efficiency of hospitals in UAE to inform future health policy formulation and reform which requires policy consistency and government institutions with strong implementation capacity. Over time, through iterative evaluation, policy review and adjustment, the UAE can identify what works best, and move to more consistent policies and standards of service delivery across its healthcare system.

\section{REFERENCES}

[1] National. Modern Uae Healthcare from a Mud Hut to Skyscraper Hospitals. 2013. Available from: http://www.thenational.ae /news/uae-news/health/modern-uae-health-care-fro m-a-mud-hut-to-skyscraper-hospitals

[2] World Health Organization. Country Cooperation Strategy for WHO and the United Arab Emirates, 2012-2017, Regional Office for the Eastern Mediterranean. 2012.

[3] National Media Council. Department of External Information. United Arab Emirates Yearbook. Abu Dhabi. 2013.

[4] Palmer S, Torgerson DJ. Definitions of efficiency. BMJ: British Medical Journal. 1999; 318(7191): 1136. PMid: 10213735. http: //dx.doi.org/10.1136/bmj.318.7191.1136

[5] Hollingsworth B, Parkin D. Developing efficiency measures for use in the NHS, A report to the NHS Executive Northern \& Yorkshire R\&D Directorate, Health Economics Group, University of Newcastle. February 1998.

[6] Charnes A, Cooper W, Rhodes E. Measuring the Efficiency of Decision Making Units. European Journal of Operational Research. 1978;
2: 429-444. http://dx.doi.org/10.1016/0377-2217(78) 9 0138-8

[7] Aigner D, Lovell CAK, Schmidt P. Formulation and estimation of stochastic frontier production functions models. Journal of Econometrics. 1977; 6: 21-37. http://dx. doi .org/10.1016/0304-4 $076(77) 90052-5$

[8] Morita H, Avkiran NK. Selecting inputs and outputs in data envelopment analysis by designing statistical experiments. Journal of the Operations Research. 2009; 52: 163-173.

[9] Nguyen KH, Coelli T. Quantifying the effects of modelling choices on hospital efficiency measures: a meta-regression analysis. University of Queensland Center for Efficiency and Productivity Analysis, Working Paper. 2009 No. WP07.

[10] Jacobs R, Smith P, Street A. Measuring Efficiency in Health Care. Cambridge: Cambridge University Press; 2006. http: //dx.doi.o rg/10.1017/CB09780511617492

[11] Eisenhardt K. Agency theory: An assessment and review. Academy of Management Review. 1989; 14: 57-74. 
[12] Jacobs P, Rapoport J. The economics of health and medical care. Sudbury, MA: Jones and Bartlett; 2003.

[13] Shleifer A, Vishny RW. Politicians and Firms. The Quarterly Journal of Economics. 1994; 109: 995-1025. http://dx.doi .org/10.23 $07 / 2118354$

[14] Weisbrod BA. The Nonprofit Economy. Cambridge, MA: Harvard University Press; 1988.

[15] Rathgeb S, Gronbjerg KA. Scope and theory of government-nonprofit relations, in: Walter W. Powell and Richard Steinberg (eds.): The nonprofit sector: a research handbook. New Haven: Yale University Press; 2006.

[16] Sloan F. Not-for-profit ownership and hospital behaviour. in: A. J. Culyer and J.P.Newhouse eds.: Handbook of Health Economics, Amsterdam, Elsevier; 2000.

[17] Hollingsworth B. The measurement of efficiency and productivity of health care delivery. Health Economics. 2008; 17: 1107-1128. PMid: 18702091. http://dx.doi.org/10.1002/hec.1391

[18] Shen Y, Eggleston K, Lau J, et al. Hospital ownership and financial performance: what explains the different findings in the empirical literature? Inquiry. 2007; 44: 41-68. PMid: 17583261. http://dx.doi.org/10.5034/inquiryjrnl_44.1.41

[19] Basu S, Andrews J, Kishore S, et al. Comparative Performance of Private and Public Healthcare Systems in Low- and Middle-Income Countries: A Systematic Review. PLoS Med. 2012; 9: e1001244. http://dx.doi.org/10.1371/journal.pmed.1001244
[20] Dorgan S, D. Layton N, Bloom R, et al. Management in Healthcare: Why good practice really matters. McKinsey and Company Report. 2007.

[21] Davies H, Mannion R, Jacobs R, et al. Exploring the Relationship between Senior Management Team Culture and Hospital Performance. Medical Care Research Review. 2007; 64: 46-65. PMid: 17213457. http://dx.doi.org/10.1177/1077558706296240

[22] Büchner VA, Schreyögg J, Schultz C. The impact of the board's strategy-setting role on board-management relations and hospital performance. Health care management review. 2014; 39(4): 305-317. PMid: 23896658. http://dx.doi.org/10.1097/HMR.0b013e3 1829 fa 10

[23] Banker R, Charnes A, Cooper W. Some Model for Estimating Technical and Scale Inefficiencies in data Envelopment Analysis. Management Science. 1984; 30: 1078-1092. http://dx.doi.org/10. 1287/mnsc. 30.9.1078

[24] Debnath R. Assessing Performance of Management Institutions: An application of DEA. The TQM Journal. 2009; 21(1): 20-33. http://dx.doi.org/10.1108/17542730910924727

[25] Joo SJ, Nixon D, Stoeberl PA. Benchmarking with data envelopment analysis: a return on asset perspective. An International Journal. 2011; 18(4): 529-542. http://dx.doi.org/10.1108/1463577 1111147623

[26] Dubai Health Authority (DHA). Dubai annual health statistics report. Dubai Health Authority. 2012.

[27] Health Authority of Abu Dhabi (HAAD). Health Authority of Abu Dhabi Statistics Report. 2012. Available from: https://www . haad .ae/haad/tabid/59/Default.aspx 